\title{
Management of Energy and Resource - Saving Innovation Projects at Agri-Food Enterprises
}

\author{
Andriy Semenov ${ }^{1}$, Ihor Kuksa ${ }^{2}$, Iryna Hnatenko ${ }^{3}$, Tetiana Sazonova ${ }^{4}$, \\ Lesya Babiy ${ }^{5}$, Viktoriia Rubezhanska ${ }^{6}$ \\ ${ }^{1}$ Classic private University, Zhukovskogo str. 70B, 69121, Zaporizhzhya, Ukraine \\ ${ }^{2}$ Kharkiv National Agrarian University named after V.V. Dokuchaiev, \\ p/o Dokuchaievske - 2, Kharkiv district, Kharkiv region, Ukraine \\ ${ }^{3}$ Kyiv National University of Technologies and Design, Nemyrovycha-Danchenka str. 2, 01011, Kyiv, Ukraine \\ ${ }^{4}$ Poltava State Agrarian Academy, Skovoroda str. 1/3, 36003, Poltava, Ukraine \\ ${ }^{5}$ Kyiv National Economic University named after Vadym Hetman, prospect Pobedy, \\ 54/1, 03057, Kyiv, Ukraine \\ ${ }^{6}$ Luhansk Taras Shevchenko National University, Gogol str. 1, 92700, Starobilsk, Ukraine
}

\begin{abstract}
The concept of innovative projects and effective management of modern enterprises in the world of agri-food sector requires a comprehensive adaptation of the management system to ensure energy and resource consumption in order to achieve competitiveness of enterprises. Since market economy tendencies encourage the spread of active policy of all resources types saving, one of the directions of which is energy and resource-saving strategy for the development of any socially oriented business entity. In this regard, the purpose of the study is to economically model the process of assessing the dynamics of financing measures for the development and implementation of innovative energy and resourcesaving projects in the agri-food sector.

Based on the construction of the above model, the main directions of management of innovative energy
\end{abstract}

DOI: $10.18421 /$ TEM102-32

https://doi.org/10.18421/TEM102-32

Corresponding author: Viktoriia Rubezhanska, Luhansk Taras Shevchenko National University,

Starobilsk, Ukraine.

Email: rubezhiik@gmail.com

Received: 22 October 2020.

Revised: 11 March 2021.

Accepted: 16 March 2021.

Published: 27 May 2021.

(cc)BY-NC-ND (C) 2021 Viktoriia Rubezhanska et al; published by UIKTEN. This work is licensed under the Creative Commons Attribution-NonCommercial-NoDerivs 4.0 License.

The article is published with Open Access at www.temjournal.com and resource-saving projects at agricultural enterprises are formulated.

Keywords - Dynamics of financing, Energy and resource saving innovations, Innovations diffusion, Management, Model, Principles, Project.

\section{Introduction}

In modern conditions of agri-food enterprises functioning new tasks of production, logistic and managerial character are solved, providing development and introduction of innovative methods as adaptive response to challenges of external environment that leads to adaptation of the specified enterprises to new conditions, and it also provides growth of economic indicators. At the same time, in the framework of effective management of their own innovative projects, the efforts of managers in agrifood enterprises should be aimed at ensuring energy and resource consumption at a competitive level, as a market economy due to competition is potentially energy and resource efficient [8], [10]. Any innovative project on energy and resource-saving in the agri-food sphere has to meet this requirement.

In general, energy and resource-saving is the optimization and economical use of all types of energy and material resources by the company based on the introduction of scientific and technological progress and effective management of innovation, the main economic result of which is additional income from reducing production costs [1], [5], [6]. It is possible to ensure a high level of energy and resource-saving at agri-food enterprises by carrying out organizational and economic measures in the areas, shown in Fig.1. 


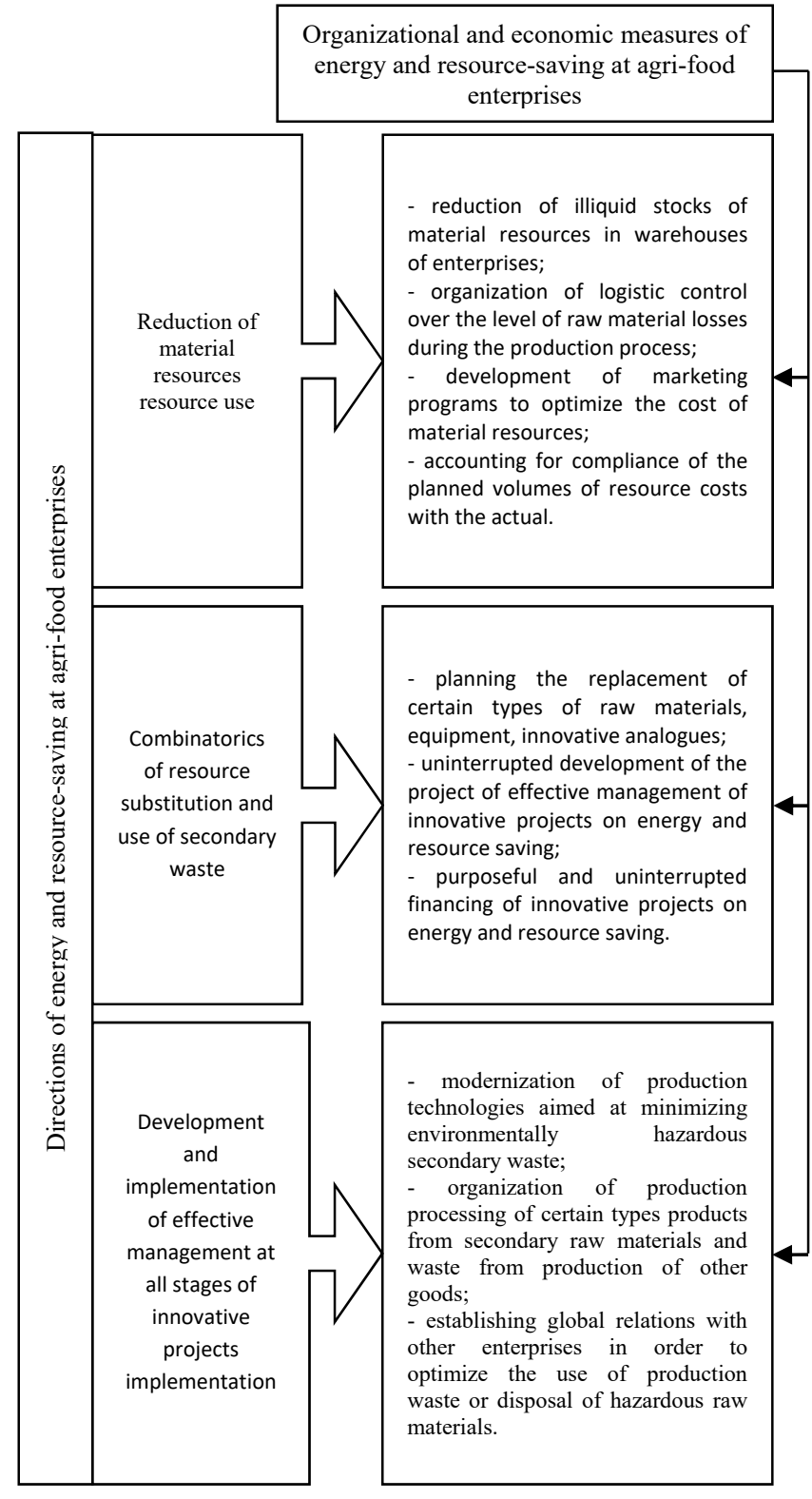

Figure 1. The Main Directions of Energy and Resourcesaving at the Enterprises of Agri-food Sphere

The implementation of the main measures shown in Figure 1 will reduce the cost of agri-food enterprises by saving the resources needed for production by using the results of progressive structural changes in the agri-industrial sector and the development of non-traditional and renewable energy sources.

\section{Literature Review}

The works of many scientists are devoted to the study of specific features of the organizing effective management process of energy and resource saving projects. Thus, He, Liao, Bi proposed a structure for optimizing management decisions on investments in energy saving measures in the process of construction companies under budget constraints [7]. Geng, Lai, Zhu based on a hierarchical regression analysis of the activities of medium and small agricultural enterprises in China found that the introduction of eco-innovation in the production process of these enterprises helps to increase productivity [4]. The article by Choi, Thangamani, Kissock proposes a matrix as the principle, with regard to resource-saving innovations efficiency to optimize the choice of projects in order to improve the efficiency of use and conservation of resources in industry [2]. The research work of McAdam, Dunn is devoted to the study of promising development of horizontal innovation networks based on resource conservation within the networks of artisanal bakeries in the agri-food sector of the United Kingdom [9]. The results of the study by Stroud, Evans, Weinel demonstrate that with the help of economic design and modularity, it is possible to implement economic innovations in Indian agri-food enterprises that create value with less resources [11]. In the article by Ting the analysis of energy saving at the enterprises-manufacturers of paper is carried out, measures on the state support of energy and resource saving at the specified enterprises by introduction of innovative technologies in manufacture are offered [12]. Dobes et al. developed a new comprehensive tool ("EDIT Value Tool") for the initial diagnosis of companies to assess resource efficiency and identify potential sources of funding for innovative projects to optimize energy and resource conservation in agricultural enterprises in Central Europe [3].

Paying tribute to the above scientific works, it should be noted the need for further research aimed at determining the conditions for intensifying the innovative activities of agri-food enterprises in the field of energy and resource-saving. In this regard, the purpose of the article is to economically model the process of assessing the dynamics of financing measures for the development and implementation of innovative energy and resource-saving projects in the agri-food sector.

\section{Research Results and Discussion}

It is believed that the management of energy and resource-saving technologies at agri-food enterprises, first of all, depends on the rapid modernization of equipment and technologies of the production process based on the use of scientific and technological progress. In this case, the main role in ensuring the stable operation and development of innovative activities of agro-industrial enterprises is played by the actual level of intensity of the flow of resources required for production activities, which reflects the following equation of innovation diffusion (1):

$$
\frac{d M_{\text {in }}}{d D_{\text {res }}} \text { or } \frac{d M_{\text {in }}}{\left(d P_{\text {res }}+d I_{\text {res }}\right)},
$$


where $d M_{\text {in }}$ - the innovation modernization level of a particular economy of the world, industry or sector of the economy;

$d D_{\text {res }}$ - the level of all investment resources of the enterprise for the implementation of the innovation project;

$d P_{\text {res }}$ - the level of available investment resources used in the economic activity of the enterprise;

$d I_{\text {res }}$ - the level of attracted investment resources by the enterprise from outside for the implementation of the innovation project.

Taking into account that $\left(d P_{\text {res }}+d I_{\text {res }}\right)$ characterizes the degree of absorption of innovations diffusion by the enterprise $\left(d D_{\text {res }}\right)$, it is obtained the following (2):

$$
\begin{aligned}
& \frac{d M_{\text {in }}}{d D_{\text {res }}}=V_{r}\left(1-M_{\text {in }}\right) \rightarrow \\
& \rightarrow M_{\text {in }}=1-e^{\int_{0}^{D_{r e s}} V_{r} d D_{\text {res }},}
\end{aligned}
$$

where $V_{r}$ - the relative rate of maximization of the innovation results perception that is equal to: $V_{r}=\psi+\tau M_{i n}$, where $\psi \mathrm{i} \tau$ - parameters of the innovation diffusion speed.

Given the above mathematical transformations, the equation for determining the level of modernization of innovations will look like (3):

$$
M_{\text {in }}=\frac{\psi\left[1-\exp \left(-\psi D_{\text {res }}-\tau D_{r e s}\right)\right]}{\psi+\tau \exp \left(-\psi D_{r e s}-\tau D_{r e s}\right)},
$$

Thus, in terms of market relations, the positive dynamics of the level of financial performance indicators in agricultural enterprises determines the possibility of introducing energy and resource-saving innovations in their production processes. In order to analyze the effectiveness of measures for the development and implementation of innovative projects of energy and resource-saving in agri-food enterprises, it is advisable to build an economic and mathematical model for assessing the dynamics of investment in the innovation diffusion.

Suppose that at a certain agri-food enterprise at a particular time $\left(t_{0 . . . i}\right)$ measures are taken to implement energy and resource-saving innovations in production activities $I_{\text {res.sav }}\left(t_{0 \ldots \mathrm{i}}\right)$. Moreover, the initial start of innovation in time is always calculated at the mark equal to 0 .

Then the initial effect of the start of innovations diffusion in the enterprise is calculated as (4):

$$
t_{0}=\max \left(t_{i}^{0}+t_{\text {in }}\right)
$$

where $t_{i}^{0}$, and $t_{0}$ - the initial effect of the innovations diffusion start in the enterprise relative to the previous period and the period following it; $t_{\text {in }}$ - duration of work.
The late term of diffusion of innovations is calculated as (5):

$$
t_{i}^{*}=\min \left(t_{n}^{*}-t_{i n}\right)
$$

where $t_{i}^{*}$ and $t_{n}^{*}$ - the late term of innovations diffusion of the previous and the following period, respectively.

In this case, the beginning of the innovation project should be accompanied by the investment of a certain amount of funds for resource conservation $F_{r e s}^{\prime}\left(t_{0 \ldots i}\right)$, and during the process $\left(t_{0 . . . \mathrm{i}}\right)$ innovation will need to attract additional funds $F_{\text {res }}^{\prime \prime}\left(t_{0 . . . \mathrm{i}}\right)$. In case of successful implementation of the innovation project at the initial or later stage of innovations diffusion due to energy and resource-saving, the agri-food enterprise will receive income $\operatorname{Inc}_{\text {econ }}\left(t_{0 . . . \mathrm{i}}\right)$, and in case of unsuccessful implementation and low management efficiency the agri-enterprise will accumulate losses, which will lead to the curtailment of the innovation project and its non-profit.

Assume that in the period $\left(t_{0 \ldots . . .}\right)$ the agricultural enterprise will accumulate profits that it received in the course of operating activities at a certain stage of the innovation project for the innovations diffusion. Then in the process of economic and mathematical modeling of estimating the dynamics of financing measures for the development and implementation of innovative energy and resource-saving projects in agri-food enterprises, we can use the hypothesis that the amount of investment in these innovations will be directly dependent on the accumulation of funds in projects realized during the term $\left(t_{0 . . \mathrm{i}}\right)$. Under such conditions, the structure of the process of implementation of energy and resource-saving innovation projects for the innovations diffusion in term $\left(t_{0 . . . \mathrm{i}}\right)$ can be represented by the following mathematical expressions (6-10):

$$
\begin{aligned}
& d I_{\text {res.sav }}^{\prime}\left(t_{0 \ldots \mathrm{i}}\right) / d\left(t_{0 \ldots \mathrm{i}}\right)=\gamma I_{\text {res.sav }}\left(t_{0 . . \mathrm{i}}\right) \\
& d I_{\text {res.sav }}^{\prime \prime}\left(t_{0 \ldots \mathrm{i}}\right) / d t_{0 \ldots \mathrm{i}}=\varphi I_{\text {res.sav }}\left(t_{0 . \ldots \mathrm{i}}\right) \\
& d I_{\text {res.sav }}\left(t_{0 \ldots \mathrm{i}}\right) / d t_{0 \ldots \mathrm{i}}= \\
& =-(\varphi+\gamma) I_{\text {res.sav }}\left(t_{0 . . \mathrm{i}}\right)+F_{r e s}^{\prime}\left(t_{0 \ldots \mathrm{i}}\right)^{-1} * \\
& * d F_{\text {res }}\left(t_{0 \ldots \mathrm{i}}\right) / d t_{0 . \ldots \mathrm{i}} \\
& d F_{\text {res }}\left(t_{0 . . . \mathrm{i}}\right) / d t_{0 \ldots \mathrm{i}}=K * d \operatorname{Inc}\left(t_{0 \ldots \mathrm{i}}\right) / d t_{0 \ldots \mathrm{i}}
\end{aligned}
$$




$$
\begin{aligned}
d \operatorname{Inc}\left(t_{0 \ldots \mathrm{i}}\right) / d t_{0 \ldots \mathrm{i}} & \\
& =\left[\operatorname{Inc}_{\text {econ }}\left(t_{0 \ldots \mathrm{i}}\right)\right. \\
& \left.-A_{\%}\left(t_{0 \ldots \mathrm{i}}\right)\right]:[1 \\
& \left.-T_{\text {rate }}\left(t_{0 \ldots \mathrm{i}}\right)\right] \\
& * d I_{\text {res.sav }}^{\prime}\left(t_{0 \ldots \mathrm{i}}\right) / d t_{0 \ldots \mathrm{i}} \\
& \\
& -F_{\text {res }}^{\prime \prime}\left(t_{0 \ldots \mathrm{i}}\right) \\
& * I_{\text {res.sav }}\left(t_{0 \ldots \mathrm{i}}\right),
\end{aligned}
$$

where: $I_{\text {res.sav }}$ - a general set of measures for the implementation and realization of energy and resource-saving innovative projects, including: $I_{\text {res.sav - a set of successfully implemented measures }}^{\prime}$

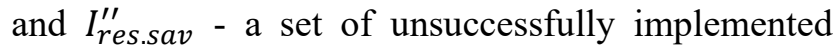
measures;

$\gamma$ and $\varphi$ - coefficients of harmony, reflecting the level of speed of energy and resource-saving innovative projects;

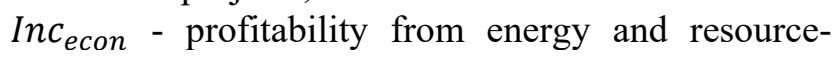
saving;

$F_{\text {res }}$ - investments attracted in the process of diffusion for the implementation of an innovative project on energy and resource conservation, consisting of the initial financing of the project at the start stage $\left(F_{\text {res }}^{\prime}\right)$ and systematic attraction of additional funds of investors during the implementation of the innovation project $\left(F_{r e s}^{\prime \prime}\right)$;

$K$ - coefficient of harmony of innovation project implementation;

Inc- the final profit received from the implementation of the innovative project of energy and resource-saving;

$A_{\%}$ - the amount of funds allocated for costs in the process of implementing an innovative project (wages, accounts payable, income tax, etc.);

$T_{\text {rate- }}$ - depreciation costs in the process of innovative project realization of the agri-industrial enterprise.

Taking into account all the mathematical equations, the process of attracting investment to the innovative energy and resource-saving project in $\left(t_{0 \ldots \mathrm{i}}\right)$ can be represented as follows (11):

$$
\begin{aligned}
& d F_{\text {res }}\left(t_{0 \ldots \mathrm{i}}\right) / d t_{0 \ldots \mathrm{i}}, \text { then: } \\
& K\left(t_{0 \ldots \mathrm{i}}\right)\left\{\left[\operatorname{In} c_{\text {econ }}\left(t_{0 \ldots \mathrm{i}}\right)-A_{\%}\left(t_{0 \ldots \mathrm{i}}\right)\right] *\right. \\
& {\left[1-T_{\text {rate }}\left(t_{0 \ldots \mathrm{i}}\right)\right] \gamma-} \\
& \left.F_{\text {res }}^{\prime \prime}\left(t_{0 \ldots \mathrm{i}}\right)\right\} I_{\text {res.sav }}\left(t_{0 \ldots \mathrm{i}}\right)
\end{aligned}
$$

In this case, for the positive dynamics of financing the innovative project on energy and resource-saving, the following condition (12) must be met:

$$
\begin{aligned}
& {\left[I n C_{e c o n}\left(t_{0 \ldots \mathrm{i}}\right)-A_{\%}\left(t_{0 \ldots \mathrm{i}}\right)\right] *[1-} \\
& \left.T_{\text {rate }}\left(t_{0 \ldots \mathrm{i}}\right)\right] \gamma-F_{\text {res }}^{\prime \prime}\left(t_{0 \ldots \mathrm{i}}\right)>0 .
\end{aligned}
$$

In the case of entering into the calculation system the indicator of the final payback of the project $R(t)=\operatorname{Inc} c_{e c o n}\left(t_{0 \ldots \mathrm{i}}\right) / F_{\text {res }}\left(t_{0 \ldots \mathrm{i}}\right) \quad$ and operating expenses $\quad C_{\text {rate }}\left(t_{0 \ldots \mathrm{i}}\right)=A_{\%}\left(t_{0 \ldots \mathrm{i}}\right) / F_{\text {res }}\left(t_{0 \ldots \mathrm{i}}\right), \quad$ the condition for implementing the effectiveness of the innovation project for the innovations diffusion aimed at energy and resource conservation will be as follows (13):

$$
\begin{aligned}
& {\left[R\left(t_{0 \ldots \mathrm{i}}\right)-C_{\text {rate }}\left(t_{0 \ldots \mathrm{i}}\right)\right] *\left[1-T_{\text {rate }}\left(t_{0 \ldots \mathrm{i}}\right)\right] *} \\
& \gamma * F_{\text {res }}\left(t_{0 \ldots \mathrm{i}}\right)-F_{\text {res }}^{\prime \prime}\left(t_{0 \ldots \mathrm{i}}\right)>0 .
\end{aligned}
$$

The need to introduce payback indicators of innovative resource-saving project $(R)$ and operating costs $\left(C_{\text {rate }}\right)$, necessary for its development and implementation, into the process of economic and mathematical modeling is due to the cost of current activities $\left(C_{\text {rate }}^{\prime}\right)$, including reimbursement interest on the loan. In this case, the values of the final payback of the project and operating costs are interdependent. However, deductions by cost elements from operating activities are inversely proportional to the payback ratio. In particular, the systematic increase in accounts payable or increase in wages significantly reduces the level and payback period of the innovation project over time $\left(t_{0 \ldots i}\right)$. It is also important to note that in case of a significant increase in operating costs (including loan settlements or an increase in income tax), the income from resource-saving in the process of implementing an innovative project will have a zero threshold. This leads to the inexpediency of further development, realization and implementation of energy and resource-saving innovations in the production process at the agri-food enterprise.

Thus, taking into account the mathematical expression (13), the process of uninterrupted investment attraction for the implementation of an innovative project on energy and resource-saving in term $\left(t_{0 \ldots \mathrm{i}}\right)$ can be reflected as follows (14):

$$
\begin{aligned}
& C_{\text {rate }}\left(t_{0 \ldots \mathrm{i}}\right)<C_{\text {rate }}^{\prime}\left(t_{0 \ldots \mathrm{i}}\right)=R\left(t_{0 \ldots \mathrm{i}}\right)- \\
& F_{\text {res }}^{\prime \prime}\left(t_{0 \ldots \mathrm{i}}\right) / \gamma\left[1-T_{\text {rate }}\left(t_{0 \ldots \mathrm{i}}\right)\right] * F_{\text {res }}
\end{aligned}
$$

To further substantiate the economic-mathematical model, we will consider in the process of operational activity invariant in terms of $\left(t_{0 . . . \mathrm{i}}\right)$ such indicators as $F_{\text {res }}^{\prime}, F_{\text {res }}^{\prime \prime}, R, C_{\text {rate }}, T_{\text {rate }}, K$, and as a result, the solution of the system of equations (6-10) will look like (15): 


$$
\begin{aligned}
& I_{\text {res.sav }}\left(t_{0 \ldots \mathrm{i}}\right)=I_{\text {res.sav }}^{\prime \prime \prime} \exp \left[\left(R-C_{\text {rate }}\right) *\right. \\
& \left(1-T_{\text {rate }}\right) * \gamma * K * F_{\text {res }} / F_{\text {res }}^{\prime}-F_{\text {res }}^{\prime \prime} / F_{\text {res }}^{\prime}- \\
& \varphi-\gamma] * t_{0 \ldots \mathrm{i}},
\end{aligned}
$$

where $I_{\text {res.sav }}^{\prime \prime \prime}$ - a set of management actions at the initial stage of realization and implementation of an innovative project on energy and resource-saving.

In this case, taking into account the mathematical expression (14), the condition of positive dynamics $(>0)$ of operating costs for an innovative project on energy and resource-saving will be as follows (16):

$$
\begin{aligned}
& \left(R-C_{\text {rate }}\right) *\left(1-T_{\text {rate }}\right) * \gamma * K * \\
& F_{\text {res }} /_{F_{\text {res }}^{\prime}}-F_{\text {res }}^{\prime \prime} / F_{\text {res }}^{\prime}-\varphi-\gamma .
\end{aligned}
$$

Based on the equation of the condition of attracting funds positive dynamics to an innovative project for energy and resource-saving in the process of operational activities (16), the critical cost of an innovative project $\left(C_{\text {rate }}^{\prime \prime}\right)$ will be $(17-18)$ :

$$
\begin{aligned}
& C_{\text {rate }}<C_{\text {rate }}^{\prime \prime}= \\
& R\left(t_{0 \ldots \mathrm{i}}\right)-F_{\text {res }}^{\prime \prime}\left(t_{0 \ldots \mathrm{i}}\right) / \gamma\left[1-T_{\text {rate }}\left(t_{0 \ldots \mathrm{i}}\right)\right]^{*} \\
& F_{\text {res }}-(1+\varphi / \gamma) * F_{\text {res }}^{\prime} /\left[\left(1-T_{\text {rate }}\right) K F_{\text {res }}\right]^{\prime} \\
& C_{\text {rate }}^{\prime \prime}= \\
& C_{\text {rate }}^{\prime}-(1+\varphi / \gamma) * F_{\text {res }}^{\prime} /\left[\left(1-T_{\text {rate }}\right) K F_{\text {res }}\right]
\end{aligned}
$$

Based on the equation (18), it can be noted that for the second condition, the critical value of operating costs will be $C_{\text {rate }}^{\prime \prime}<C_{\text {rate }}^{\prime}$. Therefore, this indicator is directly proportional to the indicators of the total payback of the innovation project, which is determined by the ratio of the coefficients of innovation projects harmony $\varphi / \gamma$.
Given the above, it is believed that to improve the management of innovative projects for energy and resource-saving in agri-food enterprises, it is necessary to take measures such as: increasing the harmonization of innovative projects by effectively allocating operating costs from current activities while developing a financing mechanism which would minimize investment risks and ultimately ensure the payback of the innovation project; search for reserves and accumulation of funds in the process of innovative projects implementing with increasing interest rates on loans, increasing income tax for agri-food enterprises; reduction of risks due to the accumulation of funds from the use of energy and resource-saving innovations in entrepreneurial activity, which will provide an opportunity to return foreign investments and interest on them in a timely manner.

\section{Conclusion}

As a result of the study, it was concluded that the harmonization of strategic management of economic entities requires the introduction of energy and resource-saving innovations in the production activities within agri-food enterprises, which is the main condition for their stable operation and competitiveness. Reduction of operating costs, their planning, rational use of labor and material resources provide a quick payback of innovative projects of agri-food enterprises in a market economy. It is believed that only those enterprises will be competitive that use in their current activities the practice of resource-saving innovation from the standpoint of a fundamentally new perspective through the reduction of production operating costs and accumulation of cash reserves. Our hypothesis formed a new view on the need to solve the focal problems of the resource use process and proved the need to implement integration measures in the current economic activity aimed at harmonizing innovative projects. Thus, the mathematical calculation of the process of implementation with regard to innovative projects aimed at energy and resource-saving, as well as their effective management, is a necessary condition for economic growth for agri-food enterprises in market conditions. 


\section{References}

[1]. Bilan, Y., Zos-Kior, M., Nitsenko, V., Sinelnikau, U., \& Ilin, V. (2017). Social component in sustainable management of land resources. Journal of Security and Sustainability Issues, 7(2), 107-120.

[2]. Choi, J. K., Thangamani, D., \& Kissock, K. (2019). A systematic methodology for improving resource efficiency in small and medium-sized enterprises. Resources, Conservation and Recycling, 147, 19-27.

[3]. Dobes, V., Fresner, J., Krenn, C., Růžička, P., Rinaldi, C., Cortesi, S., ... \& Dorer, C. (2017). Analysis and exploitation of resource efficiency potentials in industrial small and medium-sized enterprisesExperiences with the EDIT Value Tool in Central Europe. Journal of Cleaner Production, 159, 290-300.

[4]. Geng, D., Lai, K. H., \& Zhu, Q. (2021). Ecoinnovation and its role for performance improvement among Chinese small and medium-sized manufacturing enterprises. International Journal of Production Economics, 231, 107869.

[5]. Goncharov, V.M., Zos-Kior, M. \& Rakhmetulina Z. (2013). The investment component of ukrainian agrarian enterprises' development in conditions of land reform. Actual Problems of Economics, 10(148), 118-125.

[6]. Gryshko, V., Zos-Kior, M., \& Zerniuk, O. (2018). Integrating the BSC and KPI systems for improving the efficiency of logistic strategy implementation in construction companies. International Journal of Engineering and Technology (UAE), 7(3), 131-134.
[7]. He, Y., Liao, N., Bi, J., \& Guo, L. (2019). Investment decision-making optimization of energy efficiency retrofit measures in multiple buildings under financing budgetary restraint. Journal of cleaner production, 215, 1078-1094.

[8]. Hnatenko, I., Orlova-Kurilova, O., Shtuler, I., Serzhanov, V., \& Rubezhanska, V. (2020). An approach to innovation potential evaluation as a means of enterprise management improving. International Journal of Supply and Operations Management, 7(1), 112-118.

[9]. McAdam, M., McAdam, R., Dunn, A., \& McCall, C. (2014). Development of small and medium-sized enterprise horizontal innovation networks: UK agrifood sector study. International Small Business Journal, 32(7), 830-853.

[10]. Samborskyi, O., Isai, O., Hnatenko, I., Parkhomenko, O., Rubezhanska, V., \& Yershova, O. (2020). Modeling of foreign direct investment impact on economic growth in a free market. Accounting, 6(5), 705-712.

[11]. Stroud, D., Evans, C., \& Weinel, M. (2020). Innovating for energy efficiency: Digital gamification in the European steel industry. European Journal of Industrial Relations, 26(4), 419-437.

[12]. Ting, G. (2011). Researches of developing strategies and guarantee mechanism of energy saving and emission reduction on paper-making enterprises-Case study of Shandong Haiyun high-efficiency ecological park. Energy Procedia, 5, 674-678. 